\title{
O DIREITO CONSTITUCIONAL AO ADICIONAL DE INSALUBRIDADE DO SERVIDOR PÚBLICO FEDERAL EXPOSTO AO RISCO DE CONTÁGIO PELO AGENTE NOCIVO BIOLÓGICO
}

José de Oliveira Costa Filho, Aline Fonseca Franco

Universidade do Oeste Paulista - UNOESTE, curso de Direito, Presidente Prudente - SP. E-mail: josefrancoecosta@gmail.com

\section{RESUMO}

O presente objetiva discutir a validade da ON n6/2013-MPOG que orienta a concessão do adicional de insalubridade aos servidores públicos federais. Tal discussão fez-se necessária frente às restrições impostas ao direito constitucionalmente previsto aos trabalhadores em ambientes insalubres. Foram discutidos conceitos e definições de situações ensejadoras do direito ao adicional na legislação estatutária, trabalhista, literatura científica, jurisprudência e doutrina. Verificou-se vasta legislação e jurisprudência sobre o tema, especialmente quanto à interpretação dos critérios de concessão do adicional quando da existência de risco à saúde do trabalhador, mostrando-se preponderante, numa análise qualitativa, sobre a mera consideração do quantum temporal de exposição ao agente nocivo. Finalmente, face à verificação da restrição de direito fundamental por norma infra legal sem amparo nas legislações que the dão fundamento, concluiu-se que tal entendimento deverá ser revisto, visto impor prejuízo ao recebimento do adicional pelo trabalhador sem, contudo, garantir a eliminação do risco à sua saúde.

Palavras-chave: Adicional de Insalubridade, Servidores Públicos Federais, ON 6/2013 MPOG, Risco à Saúde do Trabalhador, Exposição Permanente.

\section{THE RIGHT TO CONSTITUTIONAL INSALUBRITY ADDITIONAL TO THE FEDERAL PUBLIC SERVER EXPOSED TO INFECTION RISK OF HARMFUL BIOLOGICAL AGENT}

\begin{abstract}
The article objective to discuss the validity of ON $n=6 / 2013-M P O G$ that guides the insalubrity additional pay to federal public servants. Such discussion was necessary because of restrictions on the constitutionally provided rights to workers in unhealthy environments. We discussed concepts and definitions of situations the right to further the statutory legislation, labor law, scientific literature, case law and doctrine. There was extensive legislation and jurisprudence on the subject, especially the interpretation of additional award criteria when the risk of life to workers' health, being predominant, a qualitative analysis on the consideration of the time quantum of exposure noxious agent. Finally, due to the verification of the fundamental right restriction brought by sub-legal norm no support in the laws that give them grounds, we concluded that such an understanding should be reviewed, because imposing prejudice to receipt of the additional worker without, however, guarantee the elimination of risk to your health.
\end{abstract}

Keywords: Additional for Insalubrity, Federal Public Servants, ON 6/2013 MPOG, Occupational Health at Risk, Permanent Exposure. 


\section{INTRODUÇÃO}

A motivação para o presente estudo assenta-se na recente retomada da discussão acerca do direito à percepção do adicional de insalubridade pelos servidores públicos federais expostos ao agente nocivo biológico, face às alterações nas orientações do Ministério do Planejamento, Orçamento e Gestão presentes na Orientação Normativa MPOG 06, de 18 de março de 2013, a qual revogou anterior entendimento veiculado na Orientação Normativa MPOG 02, de 19 de fevereiro de 2010.

Ocorre que com as recentes mudanças e o consequente desenquadramento de servidores ao recebimento do adicional, surgiram dúvidas quanto à adequação da recente orientação infra legal e os conceitos e definições trazidas por esta norma à literatura científica, legislação trabalhista e jurisprudência sumulada sobre o assunto.

O objetivo do presente trabalho, portanto, é a discussão da validade da recente norma infra legal frente aos conceitos legais e práticas já sedimentadas e anteriormente adotadas para a configuração ou enquadramento dos servidores em condições insalubres por exposição ao agente nocivo biológico.

\section{METODOLOGIA}

Para cumprir o objetivo proposto, o presente trabalho seguirá os métodos dialéticodedutivo, com emprego de pesquisa à legislação, literatura científica, doutrina e jurisprudência acerca da matéria objeto do estudo.

\section{RESULTADOS}

A garantia ao direito dos trabalhadores ao adicional de remuneração para atividades insalubres é de ordem constitucional, prevista no art. 7으, XXXIII, da CF.

Importante ressaltarmos que a referida previsão constitui um direito MíNIMO do trabalhador e foi alçado como direito fundamental insuscetível de supressão.

É bem anterior, contudo, o surgimento do adicional de insalubridade no Brasil, o qual foi instituído, pela primeira vez, em nosso ordenamento jurídico, pela Lei 185, de 14 de janeiro de 1936, a mesma lei que instituiu o salário mínimo e outros importantes direitos trabalhistas.

No âmbito do serviço público federal, a Lei $8112 / 90$ trouxe a normatização sobre a questão, especialmente no artigo 68, o qual reproduzimos, visto conterem relevantes termos e definições para o deslinde da questão posta em debate: 
Art. 68. Os servidores que trabalhem com habitualidade em locais insalubres ou em contato permanente com substâncias tóxicas, radioativas ou com risco de vida, fazem jus a um adicional sobre o vencimento do cargo efetivo. (grifo nosso)

Importantíssimo, ainda, apresentarmos o disposto no Decreto 97.478/89, que regulamenta a concessão dos adicionais de periculosidade e insalubridade e determina, em seu art. 1ำ, a aplicação da legislação trabalhista e, portanto, de toda a disciplina dos art. 189 a 197 da CLT, incluindo-se também a jurisprudência trabalhista, aos servidores públicos federais; e ainda discrimina, em seu art. 3으, as situações específicas que devem ser excluídas do direito à percepção do adicional de insalubridade, quais sejam, exposição esporádica e ocasional:

Art. 1ㅇ A caracterização e a classificação da insalubridade ou periculosidade para os servidores da administração federal direta, autárquica e fundacional será feita nas condições disciplinadas na legislação trabalhista.

Art. 3 Os adicionais a que se refere este Decreto não serão pagos aos servidores que:

I - no exercício de suas atribuições, fiquem expostos aos agentes nocivos à saúde apenas em caráter esporádico ou ocasional; ou

II - estejam distantes do local ou deixem de exercer o tipo de trabalho que deu origem ao pagamento do adicional. (grifo nosso).

Sobre o tema, a legislação trabalhista, em específico, a Norma Regulamentadora NR 15 do Ministério do Trabalho e Emprego - MTE, apresenta as situações que ensejam o recebimento do adicional para os trabalhadores regidos pela CLT, situações discriminadas no Anexo 14 da referida NR, onde estabelece a necessidade da verificação da permanência da exposição para enquadramento da insalubridade.

E finalmente temos a Orientação Normativa MPOG 06/2013, esta restrita à análise dos servidores públicos federais, objeto deste estudo, da qual destacamos o art. 9o, que trata da conceituação de exposição eventual, habitual e permanente, e seu anexo, que especifica as situações e percentuais de concessão do adicional de insalubridade aos servidores:

Art. 9o Em relação aos adicionais de insalubridade e periculosidade, consideram-se:

I - exposição eventual ou esporádica: aquela em que o servidor se submete a circunstâncias ou condições insalubres ou perigosas, como atribuição legal do seu cargo, por tempo inferior à metade da jornada de trabalho mensal;

II - exposição habitual: aquela em que o servidor submete-se a circunstâncias ou condições insalubres ou perigosas como atribuição legal do seu cargo por tempo igual ou superior à metade da jornada de trabalho mensal; e 
III - exposição permanente: aquela que é constante, durante toda a jornada laboral e prescrita como principal atividade do servidor;

\author{
ANEXO \\ Atividade caracterizadora de grau médio de insalubridade: (Adicional - \\ $10 \%)$
}

Trabalhos e operações em contato permanente com pacientes ou com material infectocontagiante, em hospitais, serviços de emergência, enfermarias, ambulatórios, postos de vacinação e outros estabelecimentos destinados aos cuidados da saúde humana (aplica-se unicamente ao pessoal que tenha contato com os pacientes, bem como aos que manuseiam objetos de uso desses pacientes, não previamente esterilizados).

Entende-se que o contato com paciente se caracteriza pela necessidade do contato físico e/ou manipulação de secreções para o exercício da atividade do servidor. (grifo nosso)

Assim, verifica-se que o direito ao adicional de insalubridade aos trabalhadores tem sede constitucional e se encontra regulamentado em normas que abrangem servidores públicos e empregados albergados pela legislação trabalhista.

\title{
DISCUSSÃO
}

Após análise de toda a legislação apresentada, há que ser ressaltada a inovação trazida pela ON MPOG 06/2013, referente ao conceito de "exposição permanente", que, embora mantenha, em seu art. 9, a mesma redação presente em normas anteriores do órgão (desde a ON 06/2009), restringiu, em seu anexo, ainda mais, as situações que configuram a permanência, condicionando esta à obrigatória existência de contato físico entre o servidor e o paciente.

Quanto à exigência de exposição permanente ao agente nocivo biológico, percebemos que esta encontra reflexo na NR15 do MTE, a qual, como vimos, mantém o mesmo termo em sua redação.

Há que se esclarecer, porém, que não é este o termo que encontramos no preceito legal relativo à concessão do adicional de insalubridade, qual seja, o art. 68 da Lei 8112/90 que garante o direito ao adicional aos servidores que trabalhem com HABITUALIDADE em locais insalubres.

É nesse sentido vasta jurisprudência trabalhista, a qual adota o disposto na Súmula TST n 47: "O trabalho executado em condições insalubres, em caráter intermitente, não afasta, só por essa circunstância, o direito à percepção do respectivo adicional".

Tal entendimento tem como um de seus precedentes a decisão adotada no processo 1454/72 do TST, em que considerou como preponderante a ensejar o direito ao adicional de 
insalubridade a exposição ao RISCO permanente de contaminação do trabalhador. Por relevante cita-se o raciocínio do respeitável relator:

“ [...] não há negar que a instituição da compensação do RISCO só encontra barreira na sua inexistência ou eliminação. Não será o simples fato de tratarse de exposição reduzida aos fatores insalubres que irá excluir o RISCO, pois a continuidade, ou mesmo determinadas condições, poderão acarretar consequências permanentes para a saúde do obreiro. [...] Assim, na impossibilidade de eliminação do contato com o AMBIENTE insalubre, é justo o empregado perceba o correspondente adicional. " (grifo nosso) RR, AC 3a T 1288/1972 - Min. Luiz Philippe Vieira de Melo, DJ 27/11/1972.

Vê-se, portanto, que resta sedimentado, conforme entendimentos retro citados, que o conceito de permanência para configuração de recebimento do adicional não deve estar relacionado tão e simplesmente ao tempo de exposição do trabalhador e muito menos ao mero contato físico com o paciente portador de doença infectocontagiosa.

A questão a ser considerada deve levar em conta a existência e a possibilidade de eliminação do RISCO de contágio pelo agente nocivo biológico, o qual pode-se configurar em um breve instante de exposição ao agente, independentemente de contato físico e muito menos, de um tempo prolongado de exposição. Neste sentido, conforme literatura médica, basta, para a infecção pelo agente nocivo, de um mínimo de tempo de exposição e também não se exige o contato direto com o paciente para a existência do RISCO, sendo suficiente para inúmeras patologias, como no caso da tuberculose, a aspiração de formas infecciosas do patógeno eliminados pelo doente e presentes disseminados no ambiente. (CAMPOS, 2006).

Por relevante, devemos lembrar ainda que formas de resistência de organismos patológicos podem sobreviver no ambiente externo por grandes períodos de tempo, como ficou comprovado por KRAMER, SCHWEBKE e KAMPF (2006), em seu artigo "Quanto tempo persiste viável um patógeno em ambiente hospitalar e em superfícies inanimadas? " (tradução livre), onde puderam comprovar que certos tipos de bactérias podem resistir até por anos viáveis e passíveis de infecção e que, os patógenos mais comuns resistem por períodos de algumas semanas a meses, em sua maioria.

Daí de onde percebemos a incoerência do critério adotado de contato com o paciente durante toda jornada de trabalho e, mais ainda, de contato físico com este, sendo que não é possível assegurar ao trabalhador que, evitando o contato físico ou restringindo a permanência temporal de contato com o ambiente insalubre, estará livre do RISCO de infecção.

Ademais, acrescenta que é pacífico o entendimento de que a análise da exposição ao agente nocivo biológico deve se pautar em critérios QUALITATIVOS de exposição e não 
QUANTITATIVOS, na medida em que o número ou quantidade de exposições ao agente não interfere no RISCO de PREJUÍZO À SAUDE DO TRABALHADOR, o qual, como dito, pode se dar em uma única exposição e dependerá da QUALIDADE desta exposição e do agente nocivo envolvido.

Diante disso, não há como excluir o direito do trabalhador ao adicional, uma vez que ele não tem assegurada a eliminação do RISCO causado pela exposição aos agentes nocivos biológicos decorrentes do ambiente de trabalho no qual se insere as suas atividades, ou seja, mantendo-se sob EXPOSIÇÃO HABITUAL E PERMANENTE ao RISCO de infecção durante toda sua jornada de trabalho.

Relevante ainda trazermos à baila, o disposto no Decreto 3048/99 quanto à conceituação da mesma exposição permanente aqui discutida, porém nesta normativa, para fins de fruição da aposentadoria especial advinda da realização do trabalho exposto aos agentes nocivos ou condições insalubres.

Neste sentido, em seu art. 65, o Decreto 3048/99 traz o conceito de exposição permanente sendo aquela cujo trabalho seja exercido de forma não ocasional nem intermitente e que a exposição seja INDISSOCIÁVEL da produção do bem ou da prestação do serviço, conforme a seguir reproduzido:

Art. 65. Considera-se tempo de trabalho permanente aquele que é exercido de forma não ocasional nem intermitente, no qual a exposição do empregado, do trabalhador avulso ou do cooperado ao agente nocivo seja indissociável da produção do bem ou da prestação do serviço.

Importante ainda, neste momento, destacarmos que o próprio Ministério do Planejamento, Orçamento e Gestão já reproduziu e utilizou este melhor conceito em suas normas internas, assim como vemos no parágrafo único do art. 2ำ da ON 10/2010 MPOG, conforme demostrado:

\footnotetext{
Art. 2을...]

Parágrafo único. Para efeito das disposições do caput deste artigo, considerase trabalho permanente aquele que é exercido de forma não ocasional nem intermitente, no qual a exposição do servidor ao agente nocivo seja indissociável da prestação do serviço público.
}

Assim, temos que a exposição que deve ser caracterizada como permanente é aquela obrigatória e necessária que se submete o trabalhador em virtude de seu contrato de trabalho, o qual the retira todo e qualquer grau de liberdade para recusar o exercício da atividade alegando risco de prejuízo para sua saúde. 
O Ministério da Previdência Social também já firmou este entendimento em pelo menos uma de suas normas, qual seja, o Manual de Aposentadoria Especial, aprovado pela Resolução $\mathrm{N}^{\circ}$ 196, de 25 de Abril de 2012, em que apresenta em seu texto a ideia de subordinação jurídica como fundamento da indissociabilidade entre a exposição ao agente nocivo e o trabalho do cidadão, conforme podemos conferir abaixo:

Permanência a partir de 19.3.2003: trabalho não ocasional nem intermitente - sendo excluído o termo habitual - durante quinze, vinte ou vinte cinco anos, na qual a exposição a do empregado, do trabalhador avulso ou do cooperado ao agente nocivo seja indissociável da produção do bem ou da prestação de serviço, em decorrência da subordinação jurídica a qual se submete. (grifo nosso)

Por fim, a respeito da confrontação entre os termos HABITUALIDADE e PERMANÊNCIA presentes alternadamente nas normativas, lúcido entendimento teve o Juiz Federal Ézio Teixeira do Tribunal Federal da 4ạ Região, no julgamento da Apelação Cível número 000294710.2008.404.7110/RS, no qual o eminente magistrado trata os dois termos como sinônimos, o que nos parece a melhor solução para a questão:

“(...)A habitualidade e permanência traduzem o trabalho não ocasional nem intermitente, no qual a exposição do segurado empregado, trabalhador avulso ou contribuinte individual ao agente nocivo seja indissociável à produção do bem ou à prestação do serviço. Em outras palavras, os requisitos da habitualidade e da permanência traduzem a não-eventualidade e efetividade da função insalutífera, a continuidade e a não-interrupção da exposição ao agente nocivo. "

Assim, verifica-se que a restrição trazida pela ON 06/2013 do MPOG não encontra amparo nas normas hierarquicamente superiores das quais retira seu fundamento, assim também como não se coaduna ao entendimento jurisprudencial, literatura científica e doutrina especializada. Neste sentido, não caberia limitar o direito à percepção do adicional de insalubridade à existência do contato físico, visto que permanece constante o RISCO de infecção advindo do exercício da atividade desempenhada pelo trabalhador.

Aliando-se a esse posicionamento, a condição de permanência exigida na norma deve ser entendida como aquela exposição de forma constante ao RISCO de prejuízo à saúde do trabalhador, não eventual (não esporádica ou não ocasional) não se relacionando, portanto, de forma alguma, ao tempo em que o trabalhador se mantém exposto ao agente nocivo. 


\section{CONCLUSÃO}

De todo exposto, face à constatação de que a exposição exigida pela legislação ordinária para concessão do adicional de insalubridade constitucionalmente previsto deve ser aquela exposição CONSTANTE ao RISCO de infecção e, por conseguinte, ao RISCO DE PREJUÍZO À SAÚDE do trabalhador, e não simplesmente da exposição ao agente nocivo, ou pior, da existência de contato físico entre o trabalhador e o portador de doença infecto contagiosa, temos que a restrição imposta pela orientação normativa 06/2013 MPOG viola direito fundamental na medida em que orienta a não concessão do adicional, mesmo em situações onde não há garantias de eliminação do RISCO.

É certo que a norma prevê expressamente as situações de exclusão do direito ao adicional, sendo somente aquelas em que se configura a exposição de forma EVENTUAL, ESPORÁDICA OU OCASIONAL, não cabendo estender novas hipóteses de exclusão por meio de norma infra legal.

Denota-se ainda que o fator tempo não deve ser considerado como requisito necessariamente determinante para a concessão do direito, na medida em que basta a CONSTÂNCIA do RISCO de prejuízo à saúde do trabalhador para a configuração de situação ensejadora ao recebimento do adicional.

Assim, conclui-se que a limitação imposta não deve prosperar, uma vez que em descompasso com o fim almejado pelo legislador constituinte quando da previsão do direito ao adicional de insalubridade, o que impõe ao Ministério do Planejamento, Orçamento e Gestão, a necessidade de revisão da norma aqui discutida, a fim de adequá-la aos conceitos e entendimentos já sedimentados.

\section{REFERÊNCIAS}

ALMEIDA, Amador Paes de. CLT Comentada. 5 ed. - Revista, atualizada e ampliada. São Paulo: Saraiva, 2008, p. 228-233.

AGÊNCIA NACIONAL DE VIGILÂNCIA SANITÁRIA. Nota Técnica Conjunta Nº1/2009 - SVS/MS e ANVISA. Secretário de Vigilância em Saúde. Brasília, 24 de abril de 2009. Disponível em http://www.anvisa.gov.br/hotsite/hotsite micobacteria/nota tecnica conjunta.pdf Acesso em 01.08.2015.

CAMPOS, H.S. Diagnóstico da tuberculose. Rev. Pulmão. Rio de Janeiro, v.15, n.2, 2006.

CAMPOS, H.S. Etiopatogenia da tuberculose e formas clínicas. Rev. Pulmão. Rio de Janeiro, v.15, n.1, 2006.

CASSAR, Vólia Bomfim. Direito do Trabalho. Niterói-RJ: Editora Impetus 3a Edição 2009, p 770.

DI PIETRO, Maria Sylvia Zanella. Direito Administrativo. 21 ed. São Paulo: Atlas, 2008. 
KRAMER A, SCHWEBKE I, KAMPF G: How long do nosocomial pathogens persist on inanimate surfaces? A systematic review. BMC Infect Dis 2006, 6:130.doi:10.1186/1471-2334-6-130 28

MELLO, Celso Antônio Bandeira de. Curso de direito administrativo. 22 ed. ver. Atual. São Paulo: Malheiros, 2007.

NASCIMENTO, Amauri Mascaro. Curso de Direito do Trabalho. 23 ed. São Paulo: Saraiva, 2008.

MARTINS, Sergio Pinto. Direito do Trabalho. 25. ed. São Paulo: Atlas, 2009, p. 324-325.

SUSSEKIND, Arnaldo. et. Al. Instituições de direito do trabalho. Vol. 1. São Paulo: LTR, 2001.

WORLD HEALTH ORGANIZATION. Global Tuberculosis Control: Epidemiology, Strategy, Financing. WHO publication WHO/HTM/TB/2009.441. Geneva, Switzerland, 2009. 